\title{
Protective Effects of Sodium Selenite and Vitamin-E on LPS Induced Endotoxemia of Rats
}

\author{
Dilek Pandir ${ }^{1 *}$, Fatih Oğuz Bekdemir², Züleyha Doğanyiğit' ${ }^{3}$, Sedat Per ${ }^{1}$ \\ ${ }^{l}$ Faculty of Arts and Science, Department of Biology, Bozok University, Turkey \\ ${ }^{2}$ Department of Biology, Graduate School of Natural and Applied Sciences, Bozok University, Turkey \\ ${ }^{3}$ Faculty of Medicine, Department of Histology and Embryology, Bozok University, Turkey
}

"Corresponding Author: Dilek Pandir, Faculty of Arts and Science, Department of Biology, Bozok University, Turkey,E-mail: dilek.pandir@bozok.edu.tr

\begin{abstract}
The aim of this study is to investigate the protective effect of Sodium Selenite (SS) and Vitamin E (VE) on lipopolysaccharide (LPS)-induced hepatotoxicity through oxidative stress parameters in a rat model. Only saline solution was given for control group. Single dose of LPS (10 mg/kg b.w.) was administered intraperitoneal (i.p.) to the rats for first day and the animals were treated with VE (200 $\mathrm{mg} / \mathrm{kg} \mathrm{b.w)} \mathrm{and} \mathrm{SS}$ (0.35 mg/kg b.w) plus LPS (10 mg/kg b.w.) for treatment group. Malondialdehyde (MDA) levels and antioxidant enzymes activities were detected. SOD, CAT, GPX and GST activities decreased and MDA level increased in the LPS-treated group in liver tissue $(P<0.05)$. SS and VE treatment leads to a increment of effectiveness of the antioxidant enzyme defense system. Based on findings, these changes were restored to near normal levels by VE and SS but it does not protect completely.
\end{abstract}

Keywords: LPS, Vitamin E, toxicity, antioxidant enzymes, liver, rat

\section{INTRODUCTION}

Inflammation is the reaction of the body to the unwanted state and plays important roles activitation of the primary response's cells. Macrophages are activated for local phagocytosis and released cytokines such as tumor necrosis factor (TNF- $\alpha$ ) in this process [1]. Lipopolysaccharide (LPS) is a component of the outer membrane of Gram-negative bacteria used in experimental models of inflammation. LPS stimulates proinflammatory cytokine cascades by plasma membrane proteins such as TNF- $\alpha$, NF- $\kappa$ B and IL-6 [2].

The trace element Sodium Selenite (SS) is a mineral found in the soil and naturally appears in water and some foods. It plays an important role in the safety of many biological processes because of its antigenotoxic and antimutagenic properties. SS has attracted attention because of maintaining intracellular redox balance and reducing the risk for accumulation of reactive oxygen species (ROS) in cells [3]. It may protect system from many diseases such as cancers and cardiovascular disease [4]. Several studies have shown that it has antioxidative properties that may be provide protection antioxidant capacity by increasing activities of antioxidant enzymes and by enhancing levels of the antioxidants in animals [5], plants [6], and humans [7].

Vitamin E (alfa tocopherol) (VE) is the well known lipid soluble antioxidant. It is one of the main non-enzymatic antioxidants $[8,9]$. VE is known to be the first line of the antioxidant protection [10]. Protective effect of VE has been investigated for its beneficial effect on human health, especially its antioxidant properties, and cell protective activity [10]. VE is also recognized for its anti-carcinogenic properties [11].

MDA is one of the major oxidation products of peroxidized polyunsaturated fatty acids and increased MDA content is an important indicator of LPO. Under physiological conditions, intracellular antioxidant enzymes, such as SOD, CAT, GPx, and GST, eliminate ROS, thereby playing an integral role in the antioxidative stress defenses of the cell [12]. Administration of cisplatin causes a lipid peroxide (MDA) levels and a decrease in the 
activity of enzymes that prevent or protect against the lipid peroxidation in the tissues [13].

Excessive ROS such as superoxide $\left(\mathrm{O}_{2} \cdot{ }^{-}\right)$, hydrogen peroxide $\left(\mathrm{H}_{2} \mathrm{O}_{2}\right)$, hydroxyl radical $\left(\mathrm{OH}^{-}\right)$, and peroxynitrite $\left(\mathrm{ONOO}^{-}\right)$act against various defence mechanisms, involving enzymatic (CAT, SOD, GPx, GST) and nonenzymatic systems (ascorbic acid, carotene, glutathione, tocopherol) and the biological damage occurs in cells $[14,15]$. ROS do not only harmful substances for various cells but also effects activity of biomacromolecules such as DNA [16].

The aim of this study was to determine the effect of LPS exposure on the liver tissue of male rats and to assess whether these effects can be ameliorated by co-treatment with, so called, little effects of VE and SS. To achieve this aim, rats were given LPS and VE and SS by oral gavage for six hours, then malondialdehyde (MDA) levels, SOD, CAT, GPx and GST activities in their liver tissues were assessed.

\section{Material \& Methods}

\subsection{Drugs and Chemicals}

Lipopolysaccharide (Escherichia coli LPS, serotype 0127:B8), SS and VE were purchased from Sigma Chemical Co. All other reagents were obtained from Sigma. The treatment protocol used in this study according to a previously reported [17]. LPS was dissolved in water and administered intraperitoneally. SS and VE were dissolved in water and corn oil, respectively, before use then the solution was orally administered to animals and the doses of SS and VE that were used in this study (200 and $0.35 \mathrm{mg} / \mathrm{kg}$ b.w.) were selected based on the work of Celikoğlu et al. [18] and Kalaz et al. [19].

\subsection{Animals}

Erciyes University's Experimental Animal Laboratory (HADYEK) Institute (16/133) approved experimental procedures of the study. Twenty eight male adult Wistar-Albino rats bred in laboratory. Housing was at $22-24{ }^{\circ} \mathrm{C}$ with provided 12 hours sunlight during ten days. Ad libitum feeding method was performed with standard laboratory diet. At the start of the experiment, the rats weighed $250-300 \mathrm{~g}$. They were randomly divided into control and treatment groups and housed in stainless-steel cages each containing seven rats. The experimental design was given below.

\subsection{Animal Treatment Schedule}

The rats were divided into two groups: control $(\mathrm{n}=7)$ and experimental $(\mathrm{n}=21)$ groups. Rats in the experimental group were divided into two treatment groups: Single dose of LPS intraperioneally (ip) $10 \mathrm{mg} / \mathrm{kg}$ body weight (b.w.)-treated ( $=7)$, VE $(200 \mathrm{mg} / \mathrm{kg} \mathrm{b.w})+\mathrm{SS}$ $(0.35 \mathrm{mg} / \mathrm{kg} \mathrm{b.w})$-treated $(\mathrm{n}=7), \operatorname{VE}(200 \mathrm{mg} / \mathrm{kg}$ b.w $)+$ SS $(0.35 \mathrm{mg} / \mathrm{kg} \mathrm{b.w})+$ LPS $(10 \mathrm{mg} / \mathrm{kg}$ b.w)-treated ( $n=7)$ group.

Each rat received intraperitoneal (ip) injection of $1 \mathrm{~mL}$ of $0.9 \% \mathrm{NaCl}$ saline solution $30 \mathrm{~min}$ apart as twice for control group. The substances were administered in the morning (between 09:00 and 10:00 h) to non-fasted rats. LPS, VE and SS were injected intraperitoneally, $30 \mathrm{~min}$ after normal saline administration for treatment group. At the end of the six hours of treatment, the rats in each group were weighed and then sacrificed and dissected, and tissue samples were taken to assess antioxidative defence constituents and malondialdehyde contents.

\subsection{Biochemical Evaluation}

The liver tissues were dissected and washed in sodium phosphate buffer ( $\mathrm{pH}$ 7.2). After washing, samples were taken and stored at -80 ${ }^{\circ} \mathrm{C}$ until the analysis. The tissues were homogenized using a Teflon homogenizer (Heidolph Silent Crusher $\mathrm{M}$ ), and then the homogenates were centrifuged at $10,000 \times g$ for $15 \mathrm{~min}$ at $4^{\circ} \mathrm{C}$. All processes were carried out at $4^{\circ} \mathrm{C}$. MDA content and antioxidant enzyme activities were determined by measuring the absorbance of the samples in a spectrophotometer (Shimadzu UV 1800, Kyoto, Japan).

\subsection{Assessment of Oxidative Stress}

\subsubsection{Measurement of Malondialdehyde (MDA)}

MDA content was assayed using the thiobarbituric acid (TBA) test as described by Ohkawa et al. [20]. MDA reacts with TBA to form a colored complex and these reactions were measured spectrophotometrically at 532 $\mathrm{nm}$ to measure MDA levels. The specific activity was defined as nmol per mg protein.

\subsubsection{Measurement of Superoxide Dismutase (SOD)}

SOD activity was measured as the inhibition of autoxidation of pyrogallol, according to the method of Marklund and Marklund [21]. The activity was monitored at $440 \mathrm{~nm}$ for 180s. Data is expressed as USOD/mg protein. 


\subsubsection{Measurement of Catalase (CAT)}

CAT activity in liver tissue was measured according to the method of Aebi [22] as the rate of decomposition hydrogen peroxide $\left(\mathrm{H}_{2} \mathrm{O}_{2}\right)$ at $240 \mathrm{~nm}$ for $60 \mathrm{~s}$. Data is expressed as UCAT/mg protein.

\subsubsection{Measurement of Glutathione Peroxidase} $(G P x)$

GPx activity was determined spectrophotometrically according to the method of Paglia and Valentine [24]. Briefly, reaction mixtures contained NADPH, reduced glutathione, Tris$\mathrm{HCl}$, and glutathione reductase. Reactions were initiated by the addition of $\mathrm{H}_{2} \mathrm{O}_{2}$, and $\mathrm{GPx}$ activity was measured as the change in absorbance at $340 \mathrm{~nm}$. Data is presented as $\mathrm{UGPx} / \mathrm{mg}$ protein.

\subsubsection{Measurement of Glutathione-S- transferase (GST)}

Enzyme activities of GST of liver were analysed by determination of the generation of glutathione and the 1-chloro 2,4-dinitrobenzene conjugate [24]. Increments in absorbance were stated at $340 \mathrm{~nm}$. The enzyme is represented as micromols of glutathione 1-chloro 2,4dinitrobenzene conjugate formed per minute per milligram protein.

\subsection{Protein Estimation}

The protein concentration in all samples mentioned was determined earlier by the method of Lowry et al. (1951) using bovine serum albumin as a standard [25].

\subsection{Data Analysis}

Differences among the experimental groups were analyzed by the software program SPSS 11.0 for Windows. The significance was calculated using a one-way analysis of variance (ANOVA) followed by the Tukey multiple comparison procedure. A value of $p<0.05$ was considered statistically significant.

\section{Results}

\subsection{Changes in Antioxidant Enzymes and MDA Levels}

When the LPS, LPS plus VE and SS treated groups were compared with the control group at the end of six hours, there were significantly increased in the MDA levels in the liver tissues. The MDA levels were decreased statistically significantly in the VE and SS plus LPS treated group compared to LPS treated group $(\mathrm{P}<0.05$, Figure 1).

Compared to the control group, there were statistically significantly decreased in the SOD,
CAT, GPx and GST activities in the LPS treated groups at the end of the six hours. However, SOD, CAT, GPx and GST activities was increased in LPS and VE plus SS treated groups compared with the LPS treated group in liver tissue $(\mathrm{P}<0.05$, Figures 2-5).

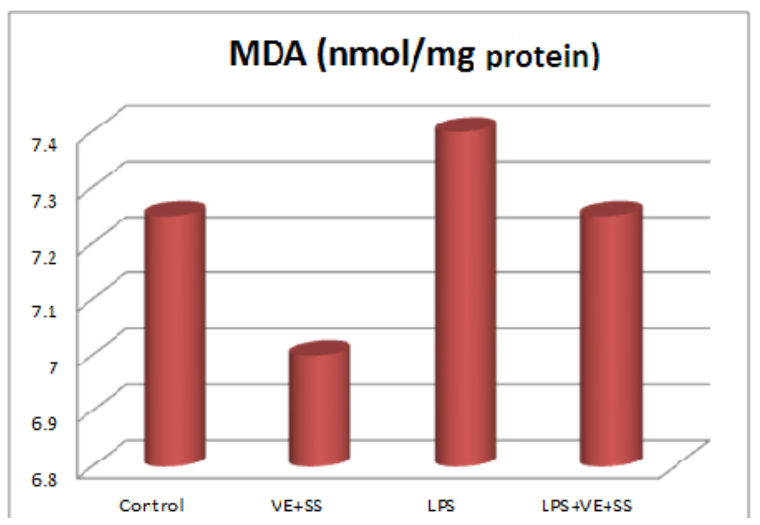

Figure1. Effects of treatment of LPS on MDA content in the liver tissues of rats. Data represents the means $\pm S D$ of seven samples. Values are mean \pm $S D$ of seven rats in each group. Significance at $P<$ 0.05 .

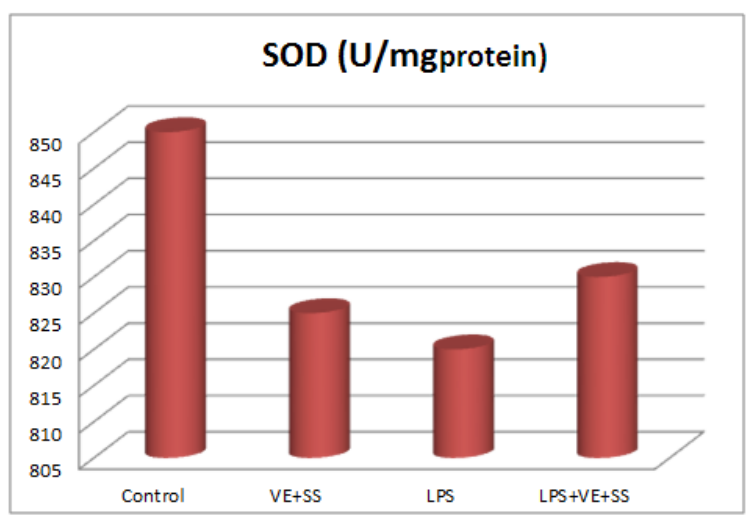

Figure2. Effects of treatment of LPS on SOD content in the liver tissues of rats. Data represents the means $\pm S D$ of seven samples. Values are mean $\pm S D$ of seven rats in each group. Significance at $P<0.05$.

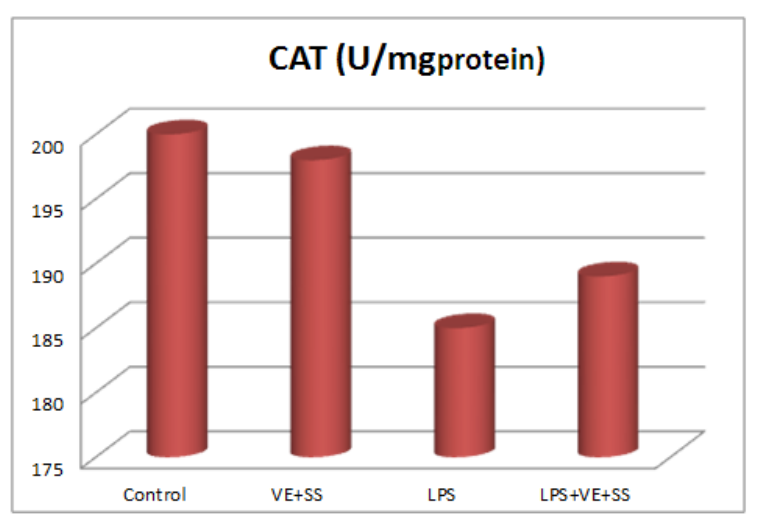

Figure 3. Effects of treatment of LPS on CAT content in the liver tissues of rats. Data represents the means $\pm S D$ of seven samples. Values are mean $\pm S D$ of seven rats in each group. Significance at $P<0.05$. 


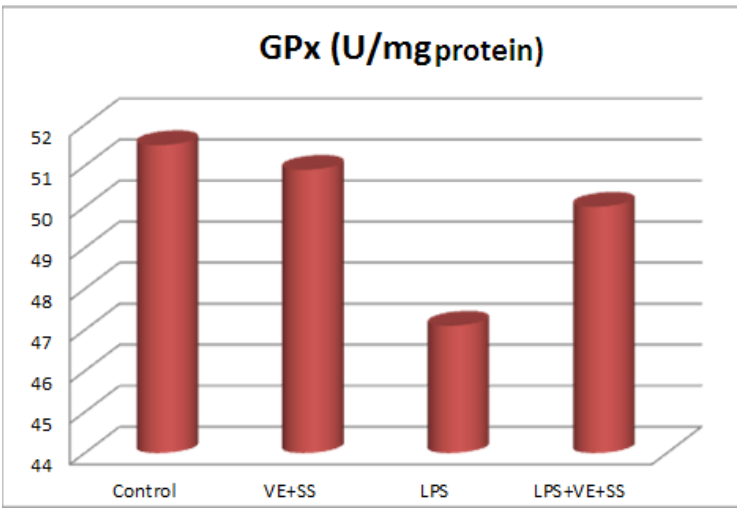

Figure 4. Effects of treatment of LPS on GPx content in the liver tissues of rats. Data represents the means $\pm S D$ of seven samples. Values are mean $\pm S D$ of seven rats in each group. Significance at $P<0.05$.

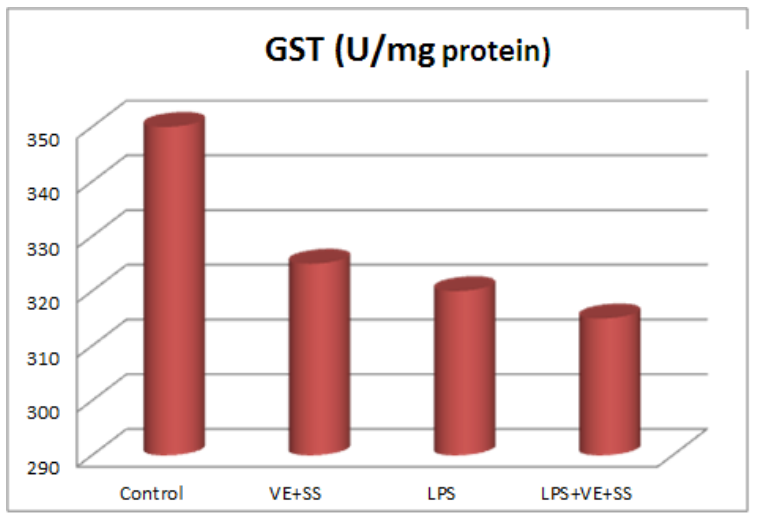

Figure 5. Effects of treatment of LPS on GST content in the liver tissues of rats. Data represents the means $\pm S D$ of seven samples. Values are mean $\pm S D$ of seven rats in each group. Significance at $P<0.05$.

\section{DISCUSSION}

Inflammation acts as an adaptive host defense mechanism against infection or injury. In inflammatory processes, macrophages are important players providing immediate defense against foreign agents [26]. Lipopolysaccharide (LPS), a component from the cell walls of gramnegative bacteria is one of the most powerful activators of macrophages and involves the production of proinflammatory cytokines [27]. Excess production of cytokines and proinflammatory mediators are involved in many inflammatory diseases and ROS [28,29]. The ROS generated during normal cellular process are immediately detoxified by endogenous antioxidants like CAT, SOD, GPx and GST etc., The enzyme superoxide dismutase (SOD) catalyzes dismutation of the superoxide anion $\left(\mathrm{O}_{2}\right)$ into hydrogen peroxide $\left(\mathrm{H}_{2} \mathrm{O}_{2}\right)$, which is then detoxified to $\mathrm{H}_{2} \mathrm{O}$ by catalase [30]. Catalase enzyme (CAT) is a common enzyme found in nearly all living organisms. Its functions include catalyzing the decomposition of hydrogen peroxide to water and oxygen [31] but excessive ROS accumulation including $\mathrm{O}_{2}{ }^{-}$, hydrogen peroxide $\left(\mathrm{H}_{2} \mathrm{O}_{2}\right)$ and $\mathrm{OH}$ by cisplatin cause an antioxidant status imblance, leads to lipid peroxidation and antioxidant enzymes depletion [32], protein denaturation and DNA damage [33,34]. Decreased activities of GPx, which scavenges hydroperoxides and lipid peroxides were found in liver of rats. LPS administration is a cause increased lipid peroxidation and a direct result of free radical damage to membrane components of the cells. VE and SS treatment (200 and $0.35 \mathrm{mg} / \mathrm{kg}$ b.w.) for six hours, starting with LPS administration, provided a significant protection against LPS induced changes in antioxidant enzymes activities by restoring them to normal.

VE are recognized as antioxidants which prevent cellular molecules from reactive oxygen species inducing damages on different biological processes such as cardiovascular disorders wound healing, age-induced oxidative stress, inflammatory responses, collagen synthesis, immune stimulation, gene expression, and enzymatic activity regulator [35]. VE is a major chain-breaking lipid soluble and known as the strong antioxidant. It is scavenger of free radicals in the cell membranes and improved histopathology. The addition of vitamin $\mathrm{E}$ to the diet at appropriate concentrations reduces thiobarbituric acid reactive substances concentration [36] and the percentage of cell abnormalities [37] but its protective activity against oxidative damage has not yet been documented in the liver tissue. The present study shows that the effect of single dose LPS exposure on the liver tissue of rats and to assess whether these effects can be ameliorated by treatment with co-treatment VE and SS.

The observed protective effect of the SS against oxidative damage of rat hepatocytes is probably due to the antioxidant properties of its moleculer structure. Moreover, the researchers show that SS has as a free radical scavenger and a potent antioxidant, both in vivo and in vitro models Kalender et al. [38] showed that treatment doses of SS has been antioxidant activities. Zao et al. [39] demonstrated that it scavenged superoxide anion and hydroxyl radicals, inhibited lipid peroxidation in rat liver in vivo. In other study, the effect of SS was investigated against oxidative damage in blood cell cultures of rat [40]. In this study, rats treated with LPS showed a decrease in liver antioxidant enzymes activities and increased MDA level. These changing of parameters was altered, but not 
competely prevented in rats by treatment with VE and SS.

Vitamin D, probolis, naringenin, Omega-3 fatty acids treatment with LPS protect against ROS in animals and humans [1, 41-44]. VE and SS complement each other in their function as antioxidants. They prevent free radical production and neutralize the free radicals that are present in the biological matrix [39]. Moreover, SS and VE protect various tissues against damages induced by free radicals [45]. The present result suggests that VE and SS is bioavailable and it possesses significant potential to prevent LPS-induced pathology and oxidative stress. Results from this study indicate that co-treatment VE and SS might be useful in ameliorating LPS induced toxicity in normal cell and has attracted considerable attention as a potential chemopreventive agent.

\section{REFERENCES}

[1] Noorbakhshnia M., Dehkordi N.G., Ghaedi K., Esmaeili A., Dabaghi M., Omega-3 fatty acids prevent LPS-induced passive avoidance learning and memory and CaMKII-a gene expression impairments in hippocampus of rat. Pharmacol. Reports. 67, 370-375 (2015).

[2] Qin L., He J., Hanes R.N., Pluzarev O., Hong J.S., Crews F.T., Increased systemic and brain cytokine production and neuroinflammation by endotoxin following ethanol treatment. J. Neuroinflammation. 5, 10 (2008).

[3] De Zoysa M., Pushpamali W.A., Oh C., Whang I., Kim S.J., Lee J., Transcriptional upregulation of disk abalone selenium dependent glutathione peroxidase by $\mathrm{H}_{2} \mathrm{O}_{2}$ oxidative stress and Vibrio alginolyticus bacterial infection. Fish Shellfish Immun. 25(4), 446-457 (2008).

[4] Kalender S., Uzun F.G., Demir F., Uzunhisarckklı M., Aslantürk A., Mercuric chloride-induced testicular toxicity in rats and the protective role of sodium selenite and vitamin E. Food Chem. Toxicol. 55, 456-462 (2013).

[5] De Zoysa M., Pushpamali W.A., Oh C., Whang I., Kim S.J., Lee J., Transcriptional upregulation of disk abalone selenium dependent glutathione peroxidase by $\mathrm{H}_{2} \mathrm{O}_{2}$ oxidative stress and Vibrio alginolyticus bacterial infection Fish. Shellfish Immun. 25(4), 446-457 (2008).

[6] Takeda T., Kondo K., Ueda K., Iida A., Antioxidant responses of selenium-enriched broccoli sprout (Brassica oleracea) to paraquat exposure, Biomed. Res. Trace Ele. 27(1), 8-14 (2016).

[7] El-Demerdash F.M., Hoda M.N., Antioxidant effect of selenium on lipid peroxidation, hyperlipidemia and biochemical parameters in rats exposed to diazinon, J. Trace. Elem. Med. Biol. 28(1), 89-93 (2014).

[8] Uzun F.G., Kalender S., Durak D., Demir F., Kalender Y., Malathion-induced testicular toxicity in male rats and the protective effect of vitamins C and E. Food Chem. Toxicol. 47, 1903-1908 (2009)

[9] El-Shawei R.A., Saleh R.M., Pharmacological effects of Vitamin C \& E on Diclofenac Sodium intoxicated rats. Biomed. Pharmacother. 84, 314-322 (2016)

[10] Eroglu S., Pandir D., Uzun F.G., Bas H., Protective role of vitamins $\mathrm{C}$ and $\mathrm{E}$ in diclorvos-induced oxidative stress in human erythrocytes in vitro. Biol. Res. 46, 33-38 (2013).

[11] Schneider C., Chemistry and biology of vitamin E. Mol. Nutr. Food Chem. 49, 7-30 (2005)

[12] Bukowska B., 2,4,5-T and 2,4,5-TCP induce oxidative damage in human erythrocytes: the role of glutathione. Cell. Biol. Interact.28, 557563 (2004).

[13] Nazıroğlu M., Karaoğlu A., Aksoy A.O., Selenium and high dose vitamin E administration protects cisplatin induced oxidative damage to renal, liver and lens tissues in rats. Toxicology. 195, 221-230 (2004).

[14] Durak D., Kalender S., Uzun F.G., Demir F., Kalender Y., Mercury chloride induced oxidative stress in human erythrocytes and the effect of vitamins $\mathrm{C}$ and $\mathrm{E}$ in vitro. African $\mathrm{J}$ Biotechnology. 9(4), 488-495 (2010).

[15] Demir F., Uzun F.G., Durak D., Kalender Y., Subacute chlorpyrifos-induced oxidative stress in rat erythrocytes and the protective effects of catechin and quercetin. Pestic. Biochem. Phys. 99, 77-81 (2011).

[16] Brieger K., Schiavone S., Miller F.J. Jr., Krause K.H., Reactive oxygen species: from health to disease, Swiss Med. Wkly. 142, w13659 (2012).

[17] Blaszcyk K., Wilczak J., Harasym J., Gudej S., Suchecka D., Krolikowski T., Lange E., Gromadzka-Ostrowska J., Impact of low and high molecular weight oat beta-glucan on oxidative stres and antioxidant defense in spleen of rats with LPS induced enteristis. Food Hydrocolloids. 51, 272-280 (2015).

[18] Celikoglu E., Aslantürk A., Kalender Y., Vitamin E and Sodium Selenite against mercuric chloride induced lung toxicity in the rats. Braz. Arch. Biol. Technol. 58(4), 587-594 (2015).

[19] Kalaz E.B., Aydın A.F., Doğan-Ekici I., Çoban J., Doğru-Abbasoğlu S., Uysal M., Protective effects of carnosine alone and together with alpha-tocopherol on lipopolysaccharide (LPS) 
plus ethanol-induced liver injury. Environ Toxicol Pharmacol. 42, 23-29 (2016).

[20] Ohkawa H., Ohishi N., Yagi K., Assay for lipid peroxides in animal tissues by thiobarbituric acid rection. Anal Biochem. 95, 351-358 (1979).

[21] Marklund S., Marklund G., Involvement of the superoxide anion radical in the autoxidation of pyrogallol and a convenient assay for superoxide dismutase. Eur. J. Biochem. 47, 469-474 (1974).

[22] Aebi H., Catalase in vitro. Methods. Enzymol. 105, 121-126 (1984).

[23] Paglia D.E., Valentine W.N., Studies on the quantative and qualitative characterization of glutathione peroxidase. J. Lab. Med. 70, 158165 (1987).

[24]Habig WH, Pabst Mj, Jakoby W.B., Glutathione-S- transferases: the first enzymatic step in mercap turic acid formation. J. Biol. Chem. 249,7130-7139 (1974).

[25] Lowry O.H., Rosebrough N.J., Farr A.L., Randall R.J., Protein measurement with the Folin phenol reagent. J. Biol Chem. 19, 265 (1951).

[26] Hwa J.L., Hyo J.L., Da Y.L., Hyeyoun J., MiRan K., Dong-Cheul M., Carabrol suppresses LPS-induced nitric oxide synthase expression by inactivation of p38 and JNK via inhibition of I-jBa degradation in RAW 264.7 cells. Biochem. Biophys. Res. Commun. 391, 14004 (2010).

[27] Nicholas C., Batra S., Vargo M.A., Voss O.H., Gavrilin M.A., Wewers M.D., Apigenin blocks lipopolysaccharide-induced lethality in vivo and proinflammatory cytokines expression by inactivating NF-kappaB through the suppression of p65 phosphorylation. J Immunol. 179, 7121-7 (2007).

[28] Lin W.W., Karin M.A., cytokine-mediated link between innate immunity, inflammation, and cancer. J Clin Invest. 117, 1175-83 (2007).

[29] Surh Y.J., Chun K.S., Cha H.H., Han S.S., Keum Y.S., Park K.K., Molecular mechanisms underlying chemopreventive activities of antiinflammatory phytochemicals: down-regulation of COX-2 and iNOS through suppression of NF- $\kappa \mathrm{B}$ activation. Mutat. Res. 480- 481, 24368 (2001).

[30] Mukherjee S., Banerjee S.K., Maulik M., Dinda A.K., Talwar K.K., Maulik S.K., Protection against adriamycin-induced cardiotoxicity by garlic: role of endogenous antioxidants and inhibition of TNF-a expression. BMC Pharmacol. 3, 1-9 (2003).

[31] Gaetani G., Ferraris A., Rolfo M., Mangerini R., Arena S., Kirkman H., Predominant role of catalase in the disposal of hydrogen peroxide within human erythrocytes. Blood. 87, 15951599 (1996).

[32] Kim Y.H., Kim Y.W., Oh Y.J., Back N.I., Chung S.A., Chung H.G., Jeong T.S., Choi M.S., Lee K.T., Protective effect of the ethanol extract of the roots of Brassica rapa on cisplatin-induced nephrotoxicity in LLC-PK 1 cells and rats. Biol. Pharm. Bull. 29, 24362441 (2006).

[33] Kim Y.K., Jung J.S., Lee S.H., Kim Y.W., Effects of antioxidants and $\mathrm{Ca}^{2+}$ in cisplatininduced cell injury in rabbit renal cortical slices. Toxicol. Appl. Pharmacol. 146, 261-269 (1997).

[34] Mora L.O., Antunes L.M., Francescato H.D., Bianchi M.L., The effects of oral glutamine on cisplatin-induced nephrotoxicity in rats. Pharmacol. Res. 47, 517-522 (2003).

[35] Mezouar D., Merzouk H., Merzouk A.S., Merzouk S.A., Belarbi B., Narce M., In vitro effects of vitamins $C$ and $E, n-3$ and n- 6 PUFA and n-9 MUFA on placental cell function and redox status in type 1 diabetic pregnant women, Placenta. 42, 114-121 (2016).

[36] Min Y., Sun T., Niu Z., Liu F., Vitamin C and vitamin $\mathrm{E}$ supplementation alleviates oxidative stress induced by dexamethasone and improves fertility of breeder roosters, Anim. Reprod. Sci. 171, 1-6 (2016).

[37] Biswas A., Mohan J., Sastry K., Effect of higher dietary vitamin Econcentrations on physical and biochemical characteristics of semen in Kadaknath cockerels, Br. Poult. Sci. 50, 733-738 (2009).

[38] Kalender S., Apaydın F.G., Uzunhisarcıklı M., Aslantürk A., Protective Role of Sodium Selenite and Vitamin E against rat erythrocytes induced by mercury chloride. GU J Sci. 27(4), 1123-1129 (2014).

[39]Zhao X., Zhou W., Jia-jun L., Chen C., Pingehuan Z., Lu D., et al. Protective effects of selenium on oxidative stress related gene expression in rat liver under chronic poisonning of arsenic. Food Chem. Toxicol. 58,1-7 (2013).

[40] Messaoudi I., Hammouda F., El Heni J., Baati T., Said K., Kerkeni A., Reversal ofcadmiuminduced oxidative stress in rat erythrocytes by selenium, zinc or their combination. Exp. Toxicol Pathol. 62, 281-288 (2010).

[41] Kumar R., Abraham A., Inhibition of LPS induced pro-inflammatory responses in RAW264.7 macrophage cells by PVP coated naringenin nanoparticle via down regulation of NF-кB/P38MAPK mediated stress signaling Pradeep. Pharmacol. Reports. (2017) (accepted).

[42] Princea P.D., Fischermana L.,Tobllic J.E., Cesar G. Fragaa C.G., Galleanoa M., LPS- 
induced renal inflammation is prevented by (-)epicatechin in rats. Redox Biology. 11, 342349 (2017).

[43] Doğanyiğit Z., Küp F.Ö., Silici S., Deniz K., Yakan B., Atayoğlu T., Protective effects of propolis on female rats' histopathological, biochemical and genotoxic changes during LPS induced endotoxemia. Phytomedicine. 15(20), 632-9 (2013).

[44] Zhang Y., Leung D.Y.M., Richers B.N., Liu Y., Remigio L.K., Riches D.W., Goleva E.,
Vitamin D inhibits monocyte/macrophage Proinflammatory Cytokine Production by Targeting MAPK Phosphatase-1. J. Immunol. March. 188(5), 2127-2135 (2012).

[45] Kalender S., Uzun F.G., Demir F., Uzunhisarcikli M., Aslanturk A., Mercuric chloride-induced testicular toxicity in rats and the protective role of sodium selenite and vitamin E. Food Chem Toxicol. 55, 456-462 (2013)

Citation: Dilek Pandir, Fatih Ŏguz Bekdemir, Züleyha Doğanyiğit, Sedat Per. Protective Effects of Sodium Selenite and Vitamin-E on LPS Induced Endotoxemia of Rats. ARC Journal of Nutrition and Growth. 2017;3(1):19-25. doi:dx.doi.org/10.20431/2455-2550.0301004.

Copyright: (C) 2017 Authors. This is an open-access article distributed under the terms of the Creative Commons Attribution License, which permits unrestricted use, distribution, and reproduction in any medium, provided the original author and source are credited. 